\title{
The many lives of an (associate) editor
}

\author{
CARMINE M. PARIANTE
}

\begin{abstract}
The role of editor of a journal attracts the vision of a scholar isolated in an ivory tower selecting "la crème" of the submitted papers, with no other preoccupations that the scientific rigour. This, is of course, only one of the many roles - or, as this editorial calls them, lives - of an editor. The essential skills are many and more complex, and an editor will encounter many problems that are related to such diverse issues as anticipating scientific trends, investigating misbehaviours, settling ethical disputes, and interfacing with the lay press. It is exciting and rewarding, and never predictable.

Declaration of Interest: None.
\end{abstract}

\section{INTRODUCTION}

As an Associate Editors of Psychological Medicine, I am delighted to contribute to this special issue on the experience of being an editor of a psychiatry journal in 2010. I have been Associated Editor from 2007: compared to my colleagues who were invited to write on the same topic in 2003 (Bebbington, 2003; Fava, 2003; Maj, 2003; Munk-Jorgensen, 2003; Paykel, 2003; Wilkinson, 2003), I cannot offer a truly "before-and-after" opinion. However, I have been a referee and an author for many years, and in my recent editorial experience I can certainly recognise and share many concepts expressed by my fellow editors in 2003. So, what is it like to be an (associate) editor of a psychiatry journal in 2010? How different is for me, now, compared with what was described by my colleagues in 2003 ?

One problem is clear: the number of papers that are written by an ever-increasing number of authors is simply gigantic. Much of this continuous tsunami gets channelled into an (also ever-increasing) number of new journals (including online-only ones). However, undoubtedly all authors strive to get their papers published in a handful of high-impact journals. Therefore, the rejection rates continue to rise, and currently it is,

Address for correspondence: Dr. C.M. Pariante, Section of Perinatal Psychiatry \& Stress, Psychiatry and Immunology, Institute of Psychiatry, Kings College London, Department of Psychological Medicine, Room 2-055, The James Black Centre, 125 Coldharbour Lane, London SE5 9NU (United Kingdom).

E-mail: carmine.pariante@kcl.ac.uk for high-impact journals, $80 \%$ or more. Interestingly, the actual rejection rate is regulated by a very simple factor: the numbers of papers that can be published in the printed version. The question is: since we now have so much more space online, why aren't we (the editors) accepting more papers? Wilkinson (2003) suggested already that we have more quality papers than we can publish; but are the high rejection rates going to stay, in order to guarantee the quality of the papers accepted?

\section{THE GUARANTOR OF THE QUALITY}

Compared to few years ago, papers published today in the same (or equivalent) journals are better: larger samples, better randomised trials, more sophisticated statistical analyses, and "denser" paper, with more variables and data. Yes - publishing in high-impact journals is becoming more and more difficult. We (the editors) are the guardians of the quality of published papers. However, while the number of papers (and of journals) is going up, good reviewers are fewer and fewer. The principle of the publication governance is (anonymous) evaluation by peer experts in the field. While this process has been the object of much debate (Wilkinson, 2003), it still remains the most accepted editorial practice. Alternative forms of quality evaluation have been proposed; for example, continuous online commentary of published papers. Will other practices one day surpass of even completely substitute peer-review? I do not know. In the meantime, all editors are complaining of the difficulty of findings good reviewers.

Epidemiologia e Psichiatria Sociale, 19, 3, 2010 


\section{THE GATEKEEPER}

There are simply too many papers to review out there. Moreover, because the (good) reviewers are so few, we (the editors) do not want to send them papers that are not of sufficient quality. So, how are we addressing this problem? The editors have become gatekeepers: anecdotally, in Psychological Medicine and in similar journals, up to $50 \%$ of papers are rejected by the editors. We do not mind doing this, as it is a win-win situation: the authors of an unsuitable paper move on quickly to another journal, and the reviewers do not get sent unsuitable papers. So why do the authors get so upset by editorial rejection? (Another question for which I do not have an answer, unfortunately). And which criteria are we using in the decisional process underlying editorial rejection? Clearly, all our decisions are driven initially by the rigorous assessment of the scientific quality of the paper. But this still does not allow us to reject enough papers (remember: $80 \%$ rejection rate). So, it is not only about scientific quality.

\section{THE JOURNALIST}

Ultimately, we want the papers we accept to have an impact. This word has been negatively associated with the "impact factor" (IF), a measure that already attracted much attention and debate in the 2003 editorials (Paykel, 2003; Wilkinson, 2003). However, IF aside, we do want the papers we accept to impact the life or our patients. To do so, the papers need to be clinically relevant and to reach an audience larger than just scientists: politicians, policy makers, patients, carers, non-governmental organisations, funding agencies. And to do so, papers should ideally be picked up by the press. "Sexiness" was already described (negatively) as part of the editorial process by Bebbington (2003). On the contrary, I think that the press is our ally. We can only accept 1 in 5 papers anyway, and certainly more than 1 in 5 are scientifically sound. Therefore, all other things considered equal, why can't we choose to publish a "sexy" paper?

\section{THE MOVIE PRODUCER}

Papers do not only need to be scientifically excellent and interesting for of a wider audience. They also need to have a clear story-line. Thousands of scripts are sent to movie production companies every year (average lengths: $120-150$ pages) and less than a dozen are made into films. How do the producers examine so many scripts? They read the first 10 pages (to see if the story can move the audience) and then they browse through the rest of the script to identify the keystones of the story-line (for example, the hero, the opponent, the object of desire, the initial defeat, the final battle). With so many papers and so little time, sometime we (the editors) have do the same: we look for papers that can move the reader (because the problem is socially or clinically important, or because it is difficult to resolve), have a clear storyline (the authors started here - and finished there) and indicate a way forward (this is what the authors mean, and this is where they want to go). Paykel (2003) already suggested that the "story" of a paper is important in the editorial process.

However, this method has potentially negative consequences. As we are getting more used to Hollywood productions, we stop enjoying movies that are difficult to understand, and we cannot any longer cope with unsettling endings. And the same is happening with scientific journals: a paper with a clear story-line always wins over papers that, instead, show doubts, scepticism, complexity and unclear immediate implications. This vicious circle further jeopardises the acceptance in high-impact journals of papers written from non-English speaking countries, especially from south-Europe, Africa and Asia (where this narrative structures is not common, and interestingly, also movies tend to be more complex and unsettling). The challenge of publishing more research from "the rest of the world" was already identified by Maj (2003); but it is very difficult now to change the preferred narrative style of the most high-impact journals. To address this challenge, we have to train scientists all over the world, to teach them the preferred writing style. Or we need to create journals that have this aim in mind, such as World Psychiatry, assertively seek such articles, and work with authors of low and middle income countries.

And then a paper will get published, right? Well, actually, the ideal paper also needs to reach the right place (the editors' desk) at the right time.

\section{THE FASHION GURU}

Trousers are no longer low-cut, and wide-genome scans are out-of-fashion too. What will be hot next year? We (the editors) must be the first to detect the new trends, because the papers we accept today cannot already be "too old" by the time they will get published in a few months. Indeed, we are the one creating the new trends. We keep our eyes and ears wide open at conferences, and

Epidemiologia e Psichiatria Sociale, 19, 3, 2010 
listen to the new ideas that are discussed. We solicit reviews and editorials by "hot" scientists and on "hot" topics. We listen carefully to posters and oral presentations, scanning for studies that would be great to publish in our journal. We accept innovative papers, which may shape the future, at the expenses of "safer" replication studies that do not shake the status quo. Referees tend to be conservatives; we (the editors) must be innovative, visionary and brave.

And what does the future look like? Even more biological, I believe. Or, better, molecular will meet social. Large-scale epidemiological, clinical and psychological studies will no longer be able to publish simple "associations" between variables, but will need to explain the biological mechanisms: why is event $\mathrm{X}$ associated with psychiatric syndrome $\mathrm{Y}$ ? Clinical phenotypes alone will also no longer be sufficient: no more cognitive tests without functional MRI, psychosocial stress without cortisol levels, physical health without inflammation, or genetic associations without molecular actions.

\section{THE DETECTIVE}

Before we accept it, a paper has to pass a final hurdle: demonstrating that it is not a salami publication. Again, this issue was clearly raised in 2003 (Bebbington, 2003; Paykel, 2003). Every time a study is conducted, many variables are collected, and many researchers are involved. There is a tension between maximising the accrual of a study in terms of number of publications, and maintaining the quality of the papers without diluting the messages into too many papers. In addition to this, we (the editors) are very sensitive to the "novelty" of a paper. Therefore, we act as detectives: through our knowledge of the literature, database search, chatting with colleagues, and of course the comments of the reviewers, we try to spot a submitted paper that is too similar to a previously published one. And our tolerance toward salami publications is getting smaller and smaller: high-impact journals in extreme cases would not accept a paper if anything from that sample has already been published, even if the submitted data are novel.

Incidentally, this editors' attitude parallels a shift in the academic environment toward evaluating researchers' performance: not by the total number of published papers, but rather by the quality and impact of the most important publications. "Fewer but better papers" is the mantra for the academics of the future. And better papers can only be obtained by putting more data into fewer publications (within the limit of the internal coherence of each paper).
OK, we have finally decided to accept a paper. Can we (the editors) relax now?

\section{THE MORAL ARBITER}

Plagiarism. Duplication of data. Plain and simple scientific fraud. Letters of complain against the reviewers. Letters of complain against the editor. Appeals against our decisions. Re-appeals against our decisions. Authors attacking other authors. Authors withdrawing from papers during the review process. Authors withdrawing from papers after it has been published. Potential libel charges. Papers coming "highly recommended" by powerful academics ("raccomandazioni"). And, of course, conflict of interest. Already in 2003 conflict of interest was discussed (Fava, 2003; Wilkinson, 2003), but this was then largely limited to concerns regarding the influence of pharmaceutical companies. However, we now know that there are many kinds of conflicts of interests: government agencies, patients' groups and non-governmental funding agencies all have their own agendas, which can influence the message of a paper. So, often we are called upon as moral arbiters. Within the limit of confidentiality, we can ask advice to other fellow editors, to senior scientists, and occasionally to specialised bodies such as the Committee on Publications Ethics (http://publicationethics.org/). But, eventually, we are the ones who have to decide what it is moral and what it is not.

\section{THE PUBLISHER}

I felt jealous when I read that Munk-Jorgensen (2003) was told that "printing, layout, circulation, dissemination, management, advertisement (...) will be taken care of in the publishing company". Today, an editor must be able to understand the technological platforms and the commercial basis of scientific publishing. Ultimately, publishers are companies and they need to make money - if they don't, they will shut the journals down and we will go home. We need to know who is subscribing to our journal, and why. For example, most subscriptions now are obtained through packages of many journals bought by institutions. University librarians can still make some choices regarding the individual journal, but usually by choosing among a few pre-packaged combinations. Some papers are sent to the membership of associations, as, for example, the British Journal of Psychiatry; but when this is not the case (as for Psychological Medicine) only a few individual subscribers still receive the journal at home. In 
the past, individual subscribers used to like even the look and the smell of the printed journal (Munk-Jorgensen, 2003): but do they still exist today? And do we want to keep them, or should we simply let them go? This is not a trivial question: individual subscribers may like items (case reports and book reviews, for example) that do not drive the paper's scientific impact and therefore may ultimately cause the loss of institutional subscribers. And then of course there is the need to understand the "competition": how can our journal maintain a position in the market, when competing with other printed, online-only, and open access journals?

\section{CONCLUSIONS}

Nothing truly prepares you for the challenges of being an editor if not the direct experience and the teaching from peers. The job that Munk-Jorgensen (2003) described as a "privilege" requires not only the profes- sional skills of many lives but also your best human skills. Rejecting papers from people you really like, or remaining calm in front of the sarcastic comments of a disgruntled author, can be truly taxing. But the satisfaction of helping the science (and the scientists) of the future overcomes all these difficult moments. I love it, and I highly recommend it!

\section{REFERENCES}

Bebbington P. (2003). Editing Social Psychiatry and Psychiatric Epidemiology. Epidemiologia e Psichiatria Sociale 12, 15-18.

Fava G.A. (2003). Conflict of interest and the credibility of medical journals. Epidemiologia e Psichiatria Sociale 12, 11-14.

Maj M. (2003). World Psychiatry: trying to reach psychiatrists worldwide. Epidemiologia e Psichiatria Sociale 12, 19-21.

Munk-Jorgensen P. (2003). The privilege of editing a scientific journal. Epidemiologia e Psichiatria Sociale 12, 2-4.

Paykel E. (2003). Editing a journal in an era of publishing change. Epidemiologia e Psichiatria Sociale 12, 9-10.

Wilkinson G. (2003). Editing the British Journal of Psychiatry. Epidemiologia e Psichiatria Sociale 12, 5-8. 